\title{
NATURALEZA DEL PROCESO ESPECIAL DE TUTELA FRENTE A LA VIOLENCIA CONTRA LA MUJER Y LOS INTEGRANTES DEL GRUPO FAMILIAR.
}

\author{
NATURE OF THE SPECIAL TRIAL IN CASES OF VIOLENCE AGAINST \\ WOMEN AND OTHER MEMBERS OF THE FAMILY GROUP
}

\section{Resumen}

José Yván Saravia Quispe ${ }^{1}$

El artículo presenta un análisis sobre la evolución en la comprensión de la naturaleza del proceso especial de tutela establecido en la Ley 30364 - Ley para Prevenir, Sancionar y Erradicar la Violencia Contra las Mujeres y los Integrantes del Grupo Familiar, señalando las dudas generadas por los vacíos procesales de la ley cuando fue promulgada y la interpretación posterior cuando entró en vigencia su reglamento, estableciendo sus principales características para que sirva de mejor comprensión al momento de ser aplicado por los operadores de justicia.

Palabras Clave: violencia contra la mujer, integrantes del grupo familiar, riesgo, ciclo de violencia, medida autosatisfactiva, proceso especial de tutela.

\section{Abstract}

This article analyzes the evolution in understanding the nature of the special trial established in Law 30364 - Law to Prevent, Punish, and Eradicate Violence Against Women and Other Members of the Family Group, pointing out the doubts generated by the procedural loopholes of such law when it was promulgated and its subsequent interpretation when its regulations came into force, establishing its main characteristics so that it is better understood when applied by the justice officials.

Keywords: violence against women, members of the family group, risk, cycle of ciolence, self-enforcing measure, special trial.

Juez Titular de Familia, Corte Superior de Justicia de Lima Este. 


\section{INTRODUCCIÓN}

El 23 de noviembre de 2015, se promulgó la Ley para Prevenir, Sancionar y Erradicar la Violencia contra las Mujeres y los Integrantes del Grupo Familiar - Ley 30364, en adelante la ley, esta nueva legislación incorporó a nuestro sistema jurídico un nuevo proceso especial de tutela con la finalidad de proteger los derechos de las víctimas de actos de violencia; sin embargo, de la redacción del artículo 16 de la ley no se llegaba a comprender con exactitud en qué consistía este proceso especial; toda vez, que no se comparaba a otros procesos similares dentro de nuestro ordenamiento procesal vigente hasta ese momento.

La redacción del referido artículo solo nos señala que "en el plazo máximo de setenta y dos horas, siguientes a la interposición de la denuncia, el juzgado de familia o su equivalente procede a evaluar el caso y resuelve en audiencia oral la emisión de las medidas de protección requeridas que sean necesarias. Asimismo, de oficio o a solicitud de la víctima, en la audiencia oral se pronuncia sobre medidas cautelares $(\ldots)$.

Entre las interrogantes que surgían en los operadores de justicia y los litigantes era de qué forma se podría llevar a cabo un proceso en un plazo tan corto sin vulnerar el derecho de las partes y contar con los medios probatorios para poder llegar a la convicción de la responsabilidad de los hechos de violencia denunciados.

Por lo tanto, se buscó cubrir el vació legal con la aplicación supletoria del Código Procesal Civil, cumpliendo con la notificación a las partes para la audiencia oral y otorgándole el derecho a la contradicción al denunciado y la actuación de medios de prueba para poder acreditar la vulneración de derecho de la supuesta víctima; ello ocasionó que de alguna forma retrocedamos al modelo anterior de la derogada ley 26260 y por supuesto, el no cumplimiento del plazo establecido en la ley.

Resultaba evidente que dicha interpretación no estaba acorde a los principios rectores de la ley en el tratamiento especial del proceso de tutela; es así, que si los tenemos en cuenta llegábamos a la conclusión que la ley busca que los operadores de justicia ante un hecho o amenaza de violencia, actúen en forma oportuna, sin dilación por razones procedimentales, formales o de otra naturaleza; ello cambiaba el panorama de la interpretación supletoria del Código Procesal Civil, porque de alguna forma este nuevo proceso establece un plazo de 72 horas, justamente porque previene que el proceso se dilate 
por cuestiones procesales o formales; más aún si también se debe aplicar el principio de sencillez y oralidad; es decir, contar un proceso de mínimo formalismo.

Entonces, quedaba más claro la naturaleza que tiene este nuevo proceso especial de tutela, pero aún no sabíamos de qué tipo de proceso estábamos presenciando en esta ley y si de alguna forma no era arbitrario restringir la formalidad procesal a su mínima expresión, para ello resulta necesario saber cómo ha ido evolucionando los procesos según la protección a la tutela urgente en nuestro país.

En el Código Procesal Civil, dentro de los procesos contenciosos contamos con el proceso Sumarísimo, que se caracteriza por contemplar los plazos más breves, la menor cantidad de actos procesales y la concentración de las audiencias en una sola, produciéndose en ese acto la expedición de la sentencia, salvo que excepcionalmente, el Juez reserve su decisión para un momento posterior. En este proceso se ventilan, por lo general, las controversias que no revisten mayor complejidad o en las que sea urgente la tutela jurisdiccional.

Este proceso es un claro ejemplo de que nuestro ordenamiento jurídico ha venido buscando la simplificación de requisitos procesales para aquellas controversias de urgente tutela. Asimismo, contamos con el Proceso Único establecido en el Código de los Niños y Adolescentes que de igual forma busca la celeridad procesal con la finalidad de resolver en plazo más breve la pretensión planteada sobre los derechos de los niños, niñas y adolescentes.

De igual forma existen procesos especiales en nuestro ordenamiento jurídico como el establecido en la Ley $\mathrm{N}^{\circ} 28457$ - Ley que regula el proceso de filiación judicial de paternidad extramatrimonial. Este proceso se inicia con la petición de quien tenga interés en obtener una declaración de paternidad y el demandado solo puede formular oposición al mandato judicial en el término de diez días y siempre que se obligue a realizarse la prueba del ADN; asimismo, este proceso refleja claramente la finalidad de nuestros legisladores a promulgar leyes adjetivas que buscan el mínimo formalismo para proteger la vulneración de derechos constitucionalmente reconocidos, un proceso donde se le otorga una obligación al emplazado que no es otra cosa a que se someta a una prueba de ADN; en caso contrario, se le considerará padre. 
Como se puede apreciar, a lo largo de la evolución de nuestro sistema procesal se ha venido prefiriendo procesos más céleres, con un mínimo de formalidad con la finalidad de resolver controversias jurídicas que ameritan tutela urgente por su propia naturaleza y porque se encuentran protegidas en la Constitución; por lo tanto, un nuevo proceso de tutela para las víctimas de violencia bajo la interpretación de sus propios principios resulta relevante y de aplicación conforme a su contexto especial; a razón de que su finalidad es proteger derechos humanos contemplados en los tratados internacionales ratificados por el Perú.

\section{INTERPRETACIÓN DE LA NATURALEZA DEL PROCESO ESPECIAL DE TUTELA.}

El 27 de julio de 2016 se publicó el Decreto Supremo N 009-2016MIMP, Reglamento de la Ley № 30364, Ley para prevenir, sancionar y erradicar la violencia contra las mujeres y los integrantes del grupo familiar, estableciendo en su artículo $6^{\circ}$ que el proceso tiene por finalidad proteger los derechos de las víctimas de actos de violencia, a través de medidas de protección o medidas cautelares, y la sanción de las personas que resulten responsable; en todas las fases del proceso se garantiza la protección de la integridad física y psicológica de las víctimas, sobre todo de aquéllas que corran riesgo de intimidación, de represalias o de victimización reiterada o repetida.

Asimismo, el reglamento también regula como instrumento la Ficha de Valoración de Riesgo cuya finalidad es detectar y medir los riesgos a los que está expuesta una víctima respecto de la persona denunciada. Su aplicación y valoración está orientada a otorgar medidas de protección con la finalidad de prevenir nuevos actos de violencia, entre ellos, el feminicidio.

Es importante señalar que los factores de riesgo son indicadores para valorar y predecir un peligro o daño futuro, lo que sucederá o no según se tomen las mejores decisiones en cada caso. Para Pueyo (2009) "la aplicación de estas técnicas han permitido cambiar las prácticas profesionales mediante la incorporación de procedimientos y técnicas que ayudan por medio de la recogida pautada y selectiva de las informaciones relevantes en la toma de decisiones de los profesionales considerando el probable futuro de comportamientos violentos. Esta anticipación de los riesgos futuros es imprescindible para realizar bien las tareas preventivas y de seguridad de la víctima". (p. 21) 
En ese sentido, quedaba claro que la ley busca que no continúen los hechos de violencia; es decir, su finalidad tutelar es interrumpir el ciclo de violencia, ello no significa que favorece a una de las partes en especial; pues si bien va direccionada a proteger la integridad de la víctima; también protege el entorno de ésta, y ello incluye al mismo denunciado porque previene futuros delitos; por lo tanto, las medidas de protección no vulnera derecho alguno al supuesto agresor, porque si con los elementos primigenios se tiene la convicción que la situación puede ser peor, la ley y el reglamento obliga frenar tal situación, ello no significa que se tenga que determinar una responsabilidad, sino paralizar el ciclo de violencia.

Al respecto, Alex Placido (2016) refiere que, "por su urgencia, la interrupción del ciclo de la violencia contra la mujer se realiza con medidas de protección que constituye un mecanismo de intervención basado en la existencia de un riesgo real que amenace derechos; esto es, que el riesgo no sea meramente hipotético o eventual o remoto, sino que tenga posibilidad cierta de materializarse de inmediato. En cambio, la investigación y castigo al autor de los actos de violencia es un mecanismo de intervención mediato, destinado a acreditar la participación en la comisión del ilícito penal y, por tanto, sancionarlo punitivamente. Como se aprecia, estos propósitos se complementan pero resultan autónomos en razón de perseguir fines distintos y valerse de medios diferentes". (p. 198)

El análisis efectuado conforme a la ley y el reglamento nos remarca que los conflictos familiares presentan como particularidad ser esencialmente humanos y mutables, conforme lo refiere Aída Kemelmajer de Carlucci (1993) en cuanto sostiene que "los conflictos de familia se diferencian de los demás conflictos entre partes, pues en la mayoría de los supuestos no se trata de resolver el litigio dando la razón a una parte y declarando culpable al otro, ni fijar quién es el ganador o el perdedor, sino que lo que ése procura es eliminar el conflicto ayudando a la familia a encontrar un nuevo orden en su estructura familiar" (p. 676)

Es así, que acorde al análisis realizado nos encontramos ante un proceso de tutela urgente que busca interrumpir el ciclo de violencia con la finalidad de proteger tanto a la víctima como su entorno familiar, incluyendo a quien se denuncia, con la finalidad de evitar nuevos hechos de violencia conforme a la determinación del riesgo en la que se encuentra. 


\section{LA TEORÍA DE UN PROCESO ESPECIAL DE TUTELA O MEDIDA AUTO SATISFACTIVA.}

Queda establecido que estamos ante un proceso especial no regulado anteriormente en nuestro ordenamiento jurídico; asimismo, la ley deja en claro que estamos ante dos formas de protección a la víctima mediante medidas de protección y medidas cautelares; asimismo, el reglamento establece que las medidas cautelares se regula conforme los requisitos establecidos en el artículo $611^{\circ}$ del Código Procesal Civil; por lo tanto, solo las medidas de protección son consideradas, por gran parte de los doctrinarios en diferentes eventos académicos, como medida autosatisfactiva.

Para Silvia Morcillo (2005) las medidas autosatisfactivas "aparecen como herramientas íntimamente ligadas a los principios que apoyan el equitativo proceso, garantizando una defensa cierta de los derechos, como la eficacia en el despacho procesal respectivo."(p.1644) Por su parte Jorge Peyrano (1997), señala que las medidas autosatisfactivas "son soluciones jurisdiccionales urgentes, autónomas, despachables inaudita et altera pars y mediando una fuerte probabilidad de que los planteos formulados sean atendibles. Importan una satisfacción definitiva de los requerimientos de sus postulantes y constituyen una especie de la tutela de urgencia que debe distinguirse de otras, como por ejemplo, de las diligencias cautelares clásicas. Pueden llegar a desempeñar un rol trascendental para remover "vías de hecho", sin tener que recurrir para tal efecto a la postulación de diligencias cautelares que, como se sabe, ineludiblemente requieren la iniciación de una pretensión principal que, a veces, no desean promover los justiciables". (p.497)

Asimismo, Galdós, Jorge (1999) indica que "la procedencia de las medidas autosatisfactivas está supeditada a la concurrencia simultánea de circunstancias infrecuentes (o sea no cotidianas) derivadas de la urgencia impostergable en la que el factor tiempo y la prontitud aparecen como perentorios; de la fuerte verosimilitud sobre los hechos, con grado de certidumbre acreditada al inicio del requerimiento o, en su caso, de sumaria comprobación; la superposición o coincidencia entre el objeto de la pretensión cautelar o preventiva -en la terminología clásica - con la pretensión material o sustancial, de modo que el acogimiento de aquella torne generalmente abstracta la cuestión a resolver porque se consumió el interés jurídico (procesal o sustancial) del peticionante." (p. 61)

Este tipo de proceso que es muy común en otros países de la región como Argentina, Uruguay, Chile entre otros, aplicable a los procesos de violencia contra la mujer e intrafamiliar, cobra fuerza en nuestra legislación 
mediante la Ley 30364 y su reglamento; por lo que resulta necesario analizar cada una de las características de este proceso con la finalidad de verificar si en efecto estamos ante un proceso de medidas autosatisfactiva y comprender su real naturaleza y el porqué de su trámite especial diferenciado de otros procesos.

\section{CARACTERÍSTICAS DEL PROCESO ESPECIAL DE TUTELA O MEDIDA AUTOSATISFACTIVA.}

Es necesario analizar si el proceso especial de tutela establecido en la Ley 30364 tiene las características que establece la doctrina comparada respecto a la medida autosatisfactiva; es así que tenemos las siguientes características:

a) Tutela urgente: En este proceso el factor tiempo constituye un elemento de suma importancia para garantizar y realizar el acceso a una justicia eficaz, cumpliendo con el principio de celeridad procesal, por lo que se requiere de un trámite expedito para crear convicción en el Juez y evitar, de esta manera, un extenso procedimiento, debate y prueba.

Mediante la ley 26260 se tramitaba el proceso de violencia familiar en la vía procedimental del proceso único, la motivación de su derogación era el ingresar a un nuevo sistema de tutela urgente; a razón de que los hechos de violencia contra la mujer y los integrantes del grupo familiar no podían ser solucionados por un instrumento vinculado a la tutela ordinaria ligada a un ritualismo procesal que en muchos de los casos no cumplía con las finalidades de la Convención Belem do Pará; es así que con la vigencia de la ley 30364 se busca enmarcar el proceso de violencia en una naturaleza especial que requiere de una oportuna decisión, de no ser así se produciría la conculcación irreversible de la integridad física y psicológica de la mujer y/o de los integrantes del grupo familiar que podría haber sido prevenida mediante una inmediata atención del sistema de justicia con el dictado de medidas de protección.

Es así que mediante la característica de urgencia expuesta legitima saltar las secuencias lógicas del proceso ordinario (demanda, contestación, prueba, sentencia) para que el pronunciamiento que se dice resulte oportuno y eficaz, sin perjuicio de la ulterior revisión del acto. Y si analizamos el artículo $16^{\circ}$ de la ley cuando nos describe el proceso especial de tutela solo nos indica que se tiene un plazo máximo de setenta y dos horas y que una vez evaluado el caso se procederá a resolver en audiencia oral la emisión de las medidas de protección requeridas que sean necesarias. Pareciera que el 
legislador se hubiera olvidado de las etapas del proceso; sin embargo, lo que pretende es incorporar al sistema de justicia un nuevo proceso especial, ello se reafirma con el principio de intervención inmediata y oportuna donde precisa que los operadores de justicia ante un hecho o amenaza de violencia, deben actuar en forma oportuna, sin dilación por razones procedimentales, formales o de otra naturaleza, disponiendo el ejercicio de las medidas de protección previstas en la ley y otras normas, con la finalidad de atender efectivamente a la víctima.

b) Autonomía: La medida autosatisfactiva debe ser entendida como un proceso autónomo y exclusivo que se agota con su emisión, no siendo necesario de otro proceso ulterior. En ese sentido, debemos tener en cuenta que la misma ley diferencia claramente la medida de protección con la medida cautelar; evidentemente, la medida cautelar está sujeta a otra pretensión principal en la vía ordinaria, pero la medida de protección que no es una cautelar no necesita de interponer otra acción, al ser dictadas procede la inmediata ejecución ante su incumplimiento.

Si bien, el proceso especial de tutela tiene una secuela con el proceso penal que finalmente determinará la culpabilidad o no del denunciado, ello no desmerece la autonomía que tiene la medida de protección dictada por el Juez de Familia; todo lo contrario, conforme lo establece el artículo 20 de la ley, el Juez Penal, una vez proceda a dictar una sentencia, si ésta es absolutoria, tendrá que analizar el caso tutelar y señalar el término de la medida de protección dispuesta por el Juez de Familia, y si su decisión es condenatoria deberá pronunciarse por las medidas de protección, incluso puede continuarlas o modificarlas; por lo tanto, las medidas dictadas son totalmente autónomas sin tener en cuenta quien es el órgano jurisdiccional que la emite o la modifica, sea el Juzgado de Familia o el Penal, porque para la ley tienen mayor relevancia la eficacia y el cumplimiento de la medida dictada que la formalidad procesal.

De igual forma el reglamento establece que los Juzgados de Familia tienen competencia para variar las medidas de protección, modificarlas de oficio o a pedido de parte cuando se produzcan hechos nuevos, si se alteran las circunstancias que motivaron la decisión o aquellas no sean suficientes para garantizar la seguridad o bienestar de la víctima o ante el incumplimiento de las medidas de protección inicialmente dictadas; ello reafirma la posición de una medida de protección autónoma que se agota con su emisión y que busca proteger de la forma más adecuada ante las diversas circunstancias que en los hechos se presenten, con la finalidad de cesar el ciclo de violencia en la etapa que se encuentre sin la necesidad 
de iniciar acciones paralelas respecto de la protección de la integridad de quien denuncia.

Finalmente toda etapa de ejecución no puede ser ejercida indeterminadamente; toda vez, que al ser una tutela urgente su función preventiva y protectora se agota cuando cumple su finalidad y esto dependerá según las circunstancias del caso en concreto; por lo que se tendrá en cuenta el plazo establecido en las resoluciones judiciales y las que se considere en el transcurso del cumplimiento de las medidas dictadas.

c) Su diligenciamiento inaudita et altera pars: La locución latina señalada literalmente significa "no oída la otra parte", y se aplica a las situaciones en las cuales el juez accede o deniega la pretensión de un litigante sin sustanciarla con el adversario. Esta característica particular ha sido bastante discutida entre los doctrinarios y los mismos jueces con la interrogante ies posible que se dicte una medida de protección sin el contradictorio?; en primer orden, por la naturaleza no cabría un contradictorio en la forma tradicional de una contestación de la demanda; sin embargo, la norma establece que las medidas se dictaran en audiencia oral, pero no queda claro que ésta incluirá la presencia del denunciado para que pueda ser oído o solo se llevará con la denunciante.

Posteriormente, el reglamento regula la etapa de la audiencia oral en su artículo 35.1., al precisar que "el Juzgado de Familia puede realizar audiencia con la sola presencia de las víctimas o sin ellas. En caso que las circunstancias lo ameriten, dicta las medidas de protección o cautelares correspondientes, en el plazo de 72 horas que establece la ley. Cuando el Juzgado lo considere necesario entrevista a la persona denunciada."

La redacción del artículo contempla tres supuestos, el primero que la audiencia se lleve con la sola presencia de la víctima y al no comparecer la misma se llevará a cabo sin ella; el segundo supuesto es que si las circunstancias lo amerita el Juez dictará las medidas de protección en el plazo establecido en la ley, por lo tanto, en ese supuesto prescindirá de la audiencia y un tercer escenario contando con la presencia del denunciado si el Juez lo considera necesario; también se puede apreciar que en ninguno de los tres supuestos el reglamento se pone en la opción de un contradictorio, porque incluso al considerar entrevistar al denunciado ésta será para generar convicción de la medida de protección más acorde al caso en concreto. Por lo tanto, el reglamento otorga una discrecionalidad al magistrado para convocar o no a la audiencia según las circunstancias que se presenten, la misma que tendrá que justificarla mediante resolución motivada. 
Ello no significa que se estaría vulnerando el derecho al debido proceso del denunciado; sino que estamos ante un contradictorio pospuesto, que podrá hacerlo valer al formular la apelación, ello a razón de la misma naturaleza del proceso urgente y porque existe una verisimilitud del derecho invocado que no es otra cosa que el riesgo de que se vuelva producir hechos de violencia.

Al respecto, Couture, citado por Vargas, Abraham Luis, (1999) enseña que "para señalar la exacta dimensión de este principio, conviene acentuar que la igualdad de las partes no es necesariamente una igualdad aritmética. Lo que este principio demanda no es una igualdad numérica sino una razonable igualdad de posibilidades en el ejercicio de la acción y defensa. Las pequeñas desigualdades requeridas por necesidades técnicas del proceso no quebrantan el principio." (p.132) Peyrano añade que "estas pequeñas desigualdades requeridas por necesidades técnicas del proceso son nada más que "restricciones temporales" al principio de contradicción pero no excepciones a su vigencia". (Citado por Vargas, 1999, p. 132)

En el proceso especial establecido en la ley contempla esta característica expresamente en el artículo 36 del reglamento cuando señala que recibido un caso de riesgo severo, de acuerdo a la Ficha de Valoración del Riesgo, el Juzgado de Familia adopta de inmediato las medidas de protección o cautelares que correspondan a favor de las víctimas. En este supuesto, la misma norma manda prescindir de la audiencia oral y emitir un pronunciamiento protector a razón del factor de riesgo.

Si bien, el contradictorio es una garantía constitucional del debido proceso de la defensa en juicio, también es verdad que en casos en que se pone en ponderación la dignidad humana, específicamente en su integridad física y psicológica es posible priorizar la tutela inmediata y postergar el contradictorio al momento de su revisión; es así, que tanto en la audiencia oral con la sola presencia de la víctima o sin ella y sin la convocación de la audiencia, el proceso especial tiene como característica dictar la medida de protección inaudita et altera pars y solo como excepción el Juez en uso de su facultad discrecional puede entrevistar al denunciado con la finalidad de generar convicción respecto a las medidas de protección a dictar.

No obstante, parte de la doctrina opina distinto señalando que como regla general debe darse un mínimo de contradicción y solo se prescindirá de ella en circunstancias especiales y autorizadas por la ley; en este sentido, Adolfo Rivas (1995) sostiene que "la sentencia anticipatoria ha de ser resultante de la sustanciación previa, como principio general, sin perjuicio de situaciones 
especiales en las que la ley pueda autorizarlos sin contradictorios" (p.21). Opina de igual forma Roland Arazi (1997), quien refiere que "estas medidas provisionales, a diferencia de las cautelares, no necesariamente se dictan sin audiencia de la contraria y tampoco persiguen asegurar el cumplimiento de una futura sentencia a dictarse, sino la satisfacción total o parcial de la pretensión, en decisión anticipada por razones de urgencia".

Asimismo, Peyrano (1999), variando su idea inicial, señala que "Además, y apartándonos un tanto de nuestros planteos iniciales, hoy creemos que si bien la regla es el despacho inaudita et altera pars de la medida autosatisfactiva, puede aceptarse que en determinadas coyunturas el tribunal interviniente puede arbitrar alguna suerte de módica sustanciación previa" (p.33). Discrepa con el criterio expuesto, María I. Riol (1999) quien propone que "la regla debería ser dotar al trámite de la autosatisfactiva de una previa y reducida sustanciación, dejando al arbitrio judicial los casos excepcionales en los que pueda resolver inaudita pars" (p.356). Continúa señalando María I. Riol que "en definitiva, el destinatario de una autosatisfactiva va a ser oído siempre. En algunos casos, previo a su dictado y en forma "reducida" si el Juez así lo considera en atención a las circunstancias particulares y materia de la medida, y en todos los casos, con posterioridad a su despacho mediante la gama de acciones de tipo impugnativo o modificatorio de la misma, pudiendo incluso explayarse en esta instancia en el aspecto probatorio de sus afirmaciones".

Particularmente, me inclino a lo señalado por Riol; toda vez, que en este modelo de proceso incorporado mediante la Ley 30364, se busca como regla general llevar acabo audiencias orales pero con la participación de la parte agraviada con la finalidad de generar convicción al Juez de Familia de la medida más acorde al riesgo de violencia; la excepción es convocar al agresor para ser entrevistado; pero sea que se le otorgue la oportunidad de hacer uso del contradictorio en su entrevista previo al dictado de la medida de protección o posteriormente mediante la impugnación de la resolución dictada, en ambos casos siempre se llega a garantizar su derecho de defensa.

A estas características descritas debemos sumar una adicional que tiene implicancia directa con la función del Juez de Familia. En este proceso especial se denota que estamos ante juez que cumple un rol imparcial pero no neutral; por lo que resulta necesario analizar el por qué la ley y el reglamento le otorga esta particularidad y si ello implica a su vez una vulneración al derecho de las partes procesales o si es válido considerar esta facultad especial al Juez de Familia. 


\section{EL JUEZ DE FAMILIA IMPARCIAL, PERO NO NEUTRAL EN EL PROCESO ESPECIAL DE TUTELA.}

No cabe duda que en un sistema democrático de justicia debe sustentarse en los principios de independencia judicial, juez natural e imparcialidad del juez. En el presente caso tomaremos en cuenta el principio de imparcialidad, el mismo que garantiza que el Juez está impedido de identificarse con las pretensiones de alguna de las partes o de sustituirse en el lugar de las mismas; su actuación será siempre de naturaleza neutral.

Queda claro que dicha garantía fundamental no puede estar ajena a la labor jurisdiccional del Juez; sin embargo, lo que la Ley 30364 y su reglamento pretende plantear que el Juez de Familia sin perder su imparcialidad se convierta en un juez no neutral con la finalidad de garantizar la protección y erradicación de la violencia contra la mujer y los integrantes del grupo familiar, debiendo analizarse si existe alguna diferencia entre imparcialidad y neutralidad, si se encuentran estrechamente unidos y si resulta procedente que el Juez de Familia deba optar por una figura de tal magnitud.

Es común relacionar que el tercero neutral de manera inversa sería la del aliado o del partidario y la actitud opuesta a la del imparcial es la del parcial; ello nos hace concluir que en esa circunstancia el sujeto pierde su condición de tercero en relación con el conflicto en cuestión. Sin embargo, conforme lo señala el profesor Aguiló Regla, (2009), "no significa que no haya diferencias entre la actitud de neutralidad y la de imparcialidad en relación con un conflicto; y estas diferencias se muestran de manera patente cuando esas dos actitudes (neutralidad e imparcialidad) vienen normativamente exigidas respecto del rol del tercero en cuestión" (p.27). Por ese motivo, a mi entender, si bien la imparcialidad y la neutralidad mantienen generalmente una unidad, su continuidad dependerá según el procedimiento y las finalidades de éste.

Continúa señalando Aguiló Regla que el “juez está llamado a dirigir el proceso y a decidir el resultado del mismo, por lo tanto, como director del proceso al juez se le exige neutralidad (equidistancia) respecto de las partes en conflicto, de forma que las decisiones que toma no prejuzguen el resultado del proceso y mantengan el equilibrio entre ellas. En esta etapa del proceso el juez debe adoptar una actitud fundamentalmente cognitiva, de recepción de información; sin embargo, en relación con el resultado del proceso al juez se le exige no que sea neutral, sino imparcial: el juez está llamado a decidir dicho resultado y, en este sentido, está comprometido con la verdad de los hechos que considera probados y con la corrección de la decisión que toma". 
En este sentido, el rol neutral del Juez se diferencia de la imparcialidad al momento que cumple su función de resolver la controversia planteada; dado que debe tomar una posición respecto a lo que durante el proceso ha observado de forma equidistante a las partes valorando los medios probatorios incorporados al proceso, sin que ello signifique que pierda su imparcialidad al momento de resolver.

Por ejemplo, en nuestro ordenamiento jurídico en el proceso laboral se sabe que el juez es imparcial en el proceso, pero los principios y reglas de fondo, acompañados y garantizados por las normas procesales, justifican el abandono de la neutralidad entendida como la asepsia de valores, en pos de la necesidad de que la igualdad de la partes en el proceso no sea solamente formal, sino real y efectiva.

Al respecto Radbruch, citado por Pla Rodríguez, (1978), anota: “La idea central en que el derecho social se inspira no es la idea de la igualdad entre las personas, sino de la nivelación de las desigualdades que entre ellas existen" (p.25); y a Couture, citado por Pla Rodríguez (1978): “El procedimiento lógico de corregir las desigualdades es el de crear otras desigualdades" (p.25).

Lo que se advierte en esta teoría es que estamos ante dos partes procesales de las cuales existen desigualdades evidentes; por lo tanto, se le reconoce al más débil derecho de tutela. Siendo ello así, para un mejoramiento en esa desigualdad, es que el juez no puede jugar un papel neutral, debiendo estar comprometido en la búsqueda de soluciones técnicas que sirvan para constituir garantías procesales de nivelación de las desigualdades que existan en un proceso, dado que dicha función no es solamente del Estado como poder político, sino también de la judicatura como parte del Estado.

Ello significa también que al momento de buscar dicha garantía procesal, debe realizarla adecuando los valores constitucionales al momento de aplicar el derecho, sin perder la imparcialidad en esa labor, dado que no depende de su subjetiva idea de lo que para él son los valores constitucionales, sino que debe aplicarlo conforme a sus conocimientos jurídicos y a la finalidad de lo que se pretende tutelar como derecho fundamental humano.

Como podemos observar, una actitud imparcial pero no neutral no es un aspecto ajeno al derecho, sino una facultad del Juez en situaciones jurídicas permitidas por la Constitución y la ley, sobre todo en procesos de tutela, cuando se observan desigualdades dentro del proceso y al momento de decidir según las circunstancias y la finalidad de la ley. En este sentido, 
debemos analizar si dicha licencia se le es permitida al Juez de Familia en el proceso especial establecido en la Ley 30364 y su reglamento; de ser así establecer cuál es el fundamento para la actuación imparcial pero no neutral en el proceso de violencia contra la mujer y los integrantes del grupo familiar.

La ley establece que en la interpretación y aplicación de esta Ley, y en general, en toda medida que adopte el Estado a través de sus poderes públicos e instituciones, así como en la acción de la sociedad, se consideran preferentemente, entre otros el principio de razonabilidad y proporcionalidad, donde el juez a cargo de cualquier proceso de violencia, debe ponderar la proporcionalidad entre la eventual afectación causada y las medidas de protección y de rehabilitación a adoptarse. Para ello, debe hacer un juicio de razonabilidad de acuerdo con las circunstancias del caso, emitiendo decisiones que permitan proteger efectivamente la vida, la salud y la dignidad de las víctimas. La adopción de estas medidas se adecúa a las fases del ciclo de la violencia y a las diversas tipologías que presentan la violencia contra las mujeres y los integrantes del grupo familiar.

Otro punto importante es el enfoque de género que contempla la ley, de esta forma el ordenamiento jurídico reconoce la existencia de circunstancias asimétricas en la relación entre hombres y mujeres, construidas sobre la base de las diferencias de género que se constituyen en una de las causas principales de la violencia hacia las mujeres; es así que mediante este enfoque no solo el estado sino también el juez, como parte de dicho estado, debe orientar el diseño de las estrategias de intervención orientadas al logro de la igualdad de oportunidades entre hombres y mujeres.

Tanto el principio y el enfoque resultan relevantes porque empiezan a incorporar pautas importantes para la toma de decisión en la medida a dictar, priorizando la protección de las víctimas y teniendo en cuenta la fase del ciclo de violencia en el que se encuentran, facultando al juez a buscar una simetría entre la denunciante y a quien se denuncia, por considerar en especial la relación entre hombres y mujeres marcadas desigualdades.

Es así que dicha facultad se encuentra contemplada como mandato constitucional conforme lo establece el artículo 2 del reglamento de la ley cuando precisa que todas las autoridades, incluyendo aquellas que pertenecen a la jurisdicción especial, tienen la responsabilidad de prevenir, sancionar y erradicar la violencia contra las mujeres y quienes integran el grupo familiar en el marco de sus competencias, en estricto cumplimiento del artículo 1 de la Constitución Política del Perú que señala que la defensa de la persona humana y el respeto de su dignidad son el fin supremo de la sociedad y el Estado. 
Es por ello que el reglamento regula diversas actuaciones de oficio por parte del juez, no solo al momento de dictar la medida de protección sino también para dictar medidas cautelares; asimismo, al momento de la ejecución de las medidas dictadas tiene amplias facultades para que sin necesidad de ser solicitadas y con la sola valoración de hechos nuevos el Juez de Familia puede variar y modificarlas, con la finalidad de asegurar el estricto cumplimiento del artículo 1 de la Constitución Política del Perú; es decir, proteger la dignidad de quien denuncia y solicita tutela urgente.

Resulta importante tener en cuenta esta característica de la naturaleza del proceso especial de tutela, donde el juez que asume la competencia de casos de violencia contra la mujer y los integrantes del grupo familiar no debe ser neutral; ello no significa que debe ser parcial, claramente debe ser imparcial, pero no es lo mismo imparcialidad que neutralidad conforme lo hemos señalado en la doctrina analizada. La razón de que el Juez de Familia no debe ser neutral es porque en aplicación de la Constitución, la ley y su reglamento debe priorizar que no sucedan más hechos de violencia; es más está obligado por la convención Belem do Pará, como funcionario público del Estado, a interrumpir el ciclo de violencia mediante la medida de protección más acorde al caso en concreto.

Esto no significa que el juez de familia mediante su resolución establezca responsabilidad del denunciado; toda vez, que no es competencia de la jurisdicción de familia sancionar, ello le corresponderá al Ministerio Público y al Juez Penal, la finalidad de la función del proceso especial de tutela ante el juez de familia es que con su accionar deba concluir o hacer que se interrumpa la situación de violencia.

Conforme a la naturaleza de este proceso especial, el dictar medidas de protección no significa un agravio al agresor, ni mucho menos vulneración a su derecho al debido proceso, significa que con los elementos iniciales que tiene el juez de familia le genere convicción de que existen factores de riesgos donde la situación denunciada puede agravarse; por lo tanto, se encuentra obligado a frenar tal situación paralizando el ciclo de la violencia. Consecuentemente, es imparcial pero no es neutral porque tiene como finalidad, como integrante y funcionario del estado, proveer las medidas más apropiadas incluso de oficio para eliminar y erradicar la violencia contra las mujeres y los integrantes del grupo familiar. 


\section{CONCLUSIÓN}

- $\quad$ El proceso especial de tutela establecido en la ley 30364 debe ser interpretado conforme a sus principios y enfoques con la finalidad de cubrir los vacíos legales.

- $\quad$ El proceso de tutela urgente busca interrumpir el ciclo de violencia con la finalidad de proteger tanto a la víctima como su entorno familiar, incluyendo a quien se denuncia, con la finalidad de evitar nuevos hechos de violencia conforme a la determinación del riesgo en la que se encuentra.

- $\quad$ El proceso especial de tutela es muy común en otros países de la región con la denominación de medida autosatisfactiva, la misma que es aplicable a los procesos de violencia contra la mujer e intrafamiliar.

- Lasmedidas autosatisfactivas son solucionesjurisdiccionales urgentes, autónomas, despachables inaudita et altera pars y mediando una fuerte probabilidad de que los planteos formulados sean atendibles.

- $\quad$ El juez que asume la competencia de casos de violencia contra la mujer y los integrantes del grupo familiar no debe ser neutral; ello a razón de que el Juez de Familia debe priorizar que no sucedan más hechos de violencia; es más está obligado por la convención Belem do Pará, como funcionario público del Estado, a interrumpir el ciclo de violencia mediante la medida de protección más acorde al caso en concreto.

\section{REFERENCIAS}

Aguiló Regla, Josep (2009). Imparcialidad y concepciones del derecho. Bogotá, Colombia : Editorial Jurid. Manizales.

Alex Placido Vilcachagua (2016). Justitia Familiae. Revista de las Comisiones Nacionales PpR Familia y de Implementación de la Ley No 30364 de la Corte Suprema de Justicia de la República del Perú. Directora Columba del Carpio Rodríguez, Jueza Suprema(Pr).

Andrés Pueyo A. (2009). La predicción de la violencia contra la pareja. Predicción del riesgo de homicidio y violencia grave en la relación de pareja. Instrumentos de evaluación del riesgo y adopción de medidas de protección. Valencia, España: Centro Reina Sofía. 
Arazi, Roland (1997). El Proceso Civil de Fin del Siglo. Derecho Procesal en Vísperas del Siglo XXI, Temas actuales en memoria de los profesores Isidoro Eisner y Joaquín Alí Salgado. Buenos Aires, Argentina: Ediar Editores.

Galdós, Jorge Mario (1999). El contenido y el continente de las medidas autosatisfactivas. Medidas Autosatisfactivas, dirigida por Jorge W. Peyrano, Santa Fe, Colombia: Editorial Rubinzal Culzoni.

Kemelmajer de Carlucci, Aída. (1993). Conf. "Principios procesales y tribunales de familia"; J.A., IV.

Pla Rodríguez (1978). Los principios del Derecho del trabajo, 2. ed., Buenos Aires, Argentina: Depalma.

Peyrano, Jorge. (1997) Reformulación de la Teoría de las Medidas Cautelares: Tutela de Urgencia. Medidas Autosatisfactorias. Ponencia realizada con motivo del XIX Congreso Nacional de Derecho Procesal. El Derecho Procesal en el Umbral del Tercer Milenio. Tomo 1. Corrientes, Argentina.

Peyrano, Jorge W (1999). Régimen de las Medidas Autosatisfactivas. Nuevas Propuestas. Parte General. Ateneo de Estudios del Proceso Civil. Buenos Aires, Argentina: Rubinzal - Culzoni Editores.

Riol, María I. (1999). La Cosa Juzgada en relación a las medidas autosatisfactivas. Medidas Autosatisfactivas. Parte General. Ateneo de Estudios del Proceso Civil. Buenos Aires, Argentina: Rubinzal - Culzoni Editores.

Rivas, Adolfo A (1997). La Jurisdicción Anticipatoria. Ponencia presentada en el XVIII Congreso Nacional de Derecho Procesal. Santa Fé, Colombia.

Morcillo Silvia (2005). Autosatisfactivas. Revista Actualidad Jurídica de Córdoba, Revista $N^{\circ} 15$.

Vargas, Abraham Luis (1999). Teoría General de los Procesos Urgentes. Medidas Autosatisfactivas. Parte General. Ateneo de Estudios del Proceso Civil. Buenos Aires, Argentina: Rubinzal - Culzoni Editores.

Fecha de recepción: 31 de agosto de 2017 Fecha de aceptación: 26 de setiembre de 2017 